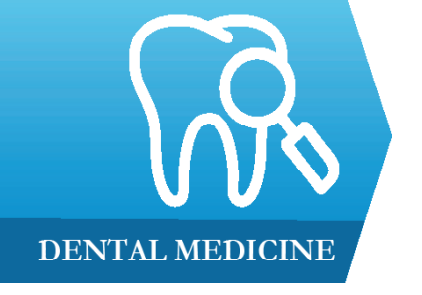

1) Department of Prosthetic Dentistry and Dental Materials, Faculty of Dental Medicine, Iuliu Hatieganu University of Medicine and Pharmacy, ClujNapoca, Romania

2) Department of Psychology, Faculty of Psychology and Educational Sciences, Babes-Bolyai University, Cluj-Napoca, Romania

3) $2^{\text {nd }}$ Medical Department, Iuliu Hatieganu University of Medicine and Pharmacy, Cluj-Napoca, Romania

\section{Oral health related quality of life and self-esteem in a general population}

\author{
Alexandru Graţian Grecu ${ }^{1}$, Robert Balazsi ${ }^{2}$, Diana Dudea ${ }^{1}$, \\ Anca Ștefania Mesaroș ${ }^{1}$, Maria Strîmbu ${ }^{1}$, Dan Lucian Dumitrașcu ${ }^{3}$
}

\begin{abstract}
Background and aims. The interest in the research of both Oral Health Related Quality Of Life and dental aesthetics has increased in the recent years. The aim of the current study consists in the evaluation of the perception of oral-health, dental aesthetics and self-esteem in a general population.

Methods. A group of students of the Faculty of Dental Medicine, Cluj-Napoca, were trained in the field of questionnaire interviewing. The students were asked to apply the following questionnaires to a number of maximum five close persons: the OHIP-14Aesthetic questionnaire, the Rosenberg self-esteem scale and a questionnaire evaluating demographic data. Each interviewed subject provided informed consent. The sample included 97 subjects with an age range of 18-75 years. For each of the three applied questionnaires overall scores were computed and used for the calculation of Pearson correlations and inferential statistical procedures: the t-test.
\end{abstract}

Results. Related to the complete sample ( $\mathrm{N}=97)$, the highest OHIP-14Aesthetic scores were obtained for the functional limitation (mean score of 2.22), physical pain (mean score of 2.72) and psychological discomfort (mean score of 1.37) subscales. The highest Rosenberg self-esteem scale scores were obtained for the following questions: "I think I am no good at all" (mean score of 3.50), "feel useless at times" (mean score of 3.53), "inclined to feel that I am a failure" (mean score 3.77), "positive attitude toward myself" (mean score of 3.50). Statistically significant correlations were registered between the overall Rosenberg self-esteem scale score and the scores of the following OHIP-14Aesthetic subscales: psychological discomfort $(r=-0.201, p=0.49)$, physical disability $(r=-0.219, p=0.031)$, psychological disability $(r=-0.218, p=0.032)$, social disability $(r=-0.203, p=0.046)$. The t-test revealed statistically significant gender differences, in regard to the OHIP-14Aesthetic overall score $\mathrm{t}(95)=-2.820, \mathrm{p}=0.006$.

Conclusions. The current study indicates the existence of statistically significant gender differences in the perception of oral health and a series of dental aesthetics elements in a general population. Moreover, statistically significant correlations were obtained between the perception of oral health and the perception of self-esteem.

Keywords: dental aesthetics, oral health related quality of life, self-esteem, questionnaire, oral health

\section{Introduction}

Oral Health Related Quality of Life (OHRQoL) represents a multidimensional construct, composed of specific domains: survival, absence of disease or any type of impairment, absence of pain, proper physical, psychological and social functioning, self-content attitude towards the own oral health, absence of social handicap [1]. OHRQoL is used in order to assess the effect of oral conditions and the effect of dental treatments on the patient's psychological state [2]. Dental and facial aesthetics represent major elements in the quality of life of patients in search for dental treatments [3]; consequently, dentofacial self-confidence has been considered an integrated part of OHRQoL [4], dental aesthetics and dento-facial attractiveness being linked with social behaviour [57]. Both OHRQoL and dental aesthetics are measured by questionnaires [8]. 
The most used OHRQoL assessment questionnaire is represented by the Oral Health Impact Profile (OHIP) [2]. The questionnaire exists in its original, 49 item form [9], as well as in shorter, 14 questions, situational adapted forms: a version for temporo-mandibular disorder [10], a version for edentulous patients [11], as well as the OHIP-14 Aesthetic form for assessing the patients' dental aesthetics, as an integrated part of the OHRQoL [12]. OHIP-14 Aesthetic was developed out of the original OHIP, as an optimized instrument of evaluating dental aesthetics issues and consequences of the dental aesthetics status upon the patients' perception, together with other OHRQoL elements [12]. OHIP-14 Aesthetic evaluates aspects regarding the attitude of patients related to dental aesthetics as well as to other oral health problems. However, OHIP-14 Aesthetic has a limited usage in the literature so far and has been validated only for China [12].

Self-esteem can be defined as the amount of selfvalue and self-acceptance of an individual [13-15]. Selfesteem has been linked to specific conditions, such as perception of a poor state of health [16], limited economic expectations [17], social exclusion [18], depression [19] or to the general quality of life $[17,20]$. Self-esteem has also been strongly related to OHRQoL [21-23] and dental aesthetics [24]. One of the most popular self-esteem assessment questionnaires is represented by the Rosenberg Self Esteem Scale (RSES) and is used in various clinical contexts: depression [25], anxiety [26], general conditions [27] and oral conditions [28].

Dental aesthetics, has been assessed, together with OHRQoL and self-esteem in correlation with various variables, such as gender $[29,30]$, age $[31,32]$ or the cultural context [33].

The aim of the current study consists of the assessment of the gender differences regarding the selfperception of the dental aesthetics, OHRQoL, dentistrelated behavior and self-esteem, using the Romanian translated versions of the OHIP-14 Aesthetic and RSES, in a general population sample. Moreover, the study intends to evaluate the interrelations between dental aesthetics, OHRQoL and self-esteem.

\section{Methods}

\section{Instruments}

The following self-reported measurements were used within the current study:

- the Romanian version of the OHIP-14 Aesthetic questionnaire; OHIP-14 Aesthetic is based on the same conceptual model as the original OHIP: Lockers conceptual model of oral health [34]. Accordingly to this model, the questions are divided in seven subscales, each investigating a specific topic: functional limitation, pain, psychological discomfort, physical disability, psychological disability, social disability and handicap. Each subscale contains two questions. The extended questions, belonging to each subscale, are presented in Appendix 1. Answers to the questions are ordered on a Likert scale, with answer options and encodings ranging from "Never" - 0 to "Very often" -4 . The questionnaire scores are calculated as subscale and overall scores, by summing the scores for each question comprised within a subscale the questionnaire was applied in accordance to Wong's indications [12]; OHIP-14 Aesthetic was applied in order to assess the self-perception of the dental aesthetics, as a component of the OHRQoL; the questionnaire's internal consistency has been tested on the current sample, with a Cronbach's Alpha of 0.88, value which is accordance with the one reported in the original OHIP-14 Aesthetic development study [12];

- the Romanian translation of the RSES. The RSES contains 10 questions investigating the respondent's self-esteem. The answers to the questions are organized on a Likert scale, ranging from "Strongly agree" - 1 to "Strongly disagree" -4 . The questions $2,5,6,8,9$ receive inverted scoring, due to negative question formulation [35]. The RSES was applied according to the guidelines [35]; the questionnaire's internal consistency has been tested on the current sample, with a Cronbach's Alpha of 0.88 , value which is corresponding with other literature reported values [36].

- an additional questionnaire evaluating:

- socio-demographic variables: gender, age, living place, education, occupation, marital status;

- eating habits; dental hygiene habits;

- the subjects' interaction with the dentist; the frequency of the dental visits, within the last 5 years; the occurrence of the last dental visit; the main reason for presentation within the dental office; the quality of the communication with the dentist;

Each of these comprising questions presented multiple choice answers; the subjects had to choose one answer.

\section{Design, participants and procedure}

The current study was designed as a cross sectional survey. The current study was conducted with the ethics approval of the Iuliu Hatieganu University of Medicine and Pharmacy, Cluj-Napoca. 28 dental students from the $2^{\text {nd }}$ study year (enrolled in the Faculty of Dental Medicine, Iuliu Hatieganu University of Medicine and Pharmacy) were trained as interviewers for the current study. During the training process, the students became familiar with the structure of the three questionnaires, together with the form of consent; additionally they learned how to conduct a questionnaire interview, how to select the information needed to be specified to the patients and the way in which they should address possible questions from the side of the patients; moreover the students were informed they needed to observe the maximum interview duration of 20 minutes. Each student was asked to apply the 3 abovedescribed questionnaires to 4 subjects (relatives, friends, 
acquaintances). The students were involved in this study based on volunteer participation. The interview format was chosen, in order to minimize the rate of unanswered questions. Thus, the sample was chosen based on the convenience sample criteria, meeting the following inclusion criteria: both genders; an age interval of 18-75 years; urban or rural living environment; inferior study limit: middle school; unaltered communicational and cognitive abilities.

The final sample included 97 participants and presented the following characteristics: $40.2 \% \mathrm{M}, 59.79 \%$ $\mathrm{F}$ and an age range of 19-72 years.

During a period two weeks, the students applied the questionnaires under the interview format. Each patient provided informed consent and had to choose only one answer option for each question.

Each response option received a numbered coding and the scores were calculated as following:

- in respect to the OHIP-14 Aesthetic questionnaire, the seven subscale scores were calculated, together with an OHIP-14 Aesthetic overall score; higher scores indicated a poorer OHRQoL;

- in respect to the RSES, an overall score was calculated; higher scores indicated a higher self-esteem;

- for the additional questionnaire, comprising demographic data, information regarding eating and dental habits, information regarding the communication with the dentist and dental visits, the answer frequency was calculated.

\section{Data analysis}

Following the data systematizing in a Microsoft Excel table, the scores for the three applied questionnaires were calculated, in accordance to the previous described guidelines.

Firstly, univariate descriptive statistical procedures were employed, with mean scores and standard deviation being calculated for the OHIP-14 Aesthetic subscales and overall questionnaire, as well as for the RSES. Secondly, Persons correlations were calculated, as following:

- between the OHIP-14 Aesthetic subscale/overall scores and the RSES overall scores;

- between the OHIP-14 Aesthetic subscale/overall scores and the dental hygiene/eating habits/interaction with de dentist questions scores.

Thirdly, inferential statistical procedures were applied, employing the t-test. The t-test evaluated:

- subscale/overall OHIP-14 Aesthetic scores differences between the male and female subjects; overall RSES scores differences between the male and female subjects;

- dental hygiene/eating habits/interaction with de dentist questions scores between the male and female subjects.

\section{Results \\ Descriptive statistics}

General data and answers to the questionnaire assessing demographic data, eating habits and oral hygiene habits are presented in table I.

Table I. Demographic data, eating habits, dental hygiene habits overall sample $(\mathrm{n}=97)$.

\begin{tabular}{|c|c|}
\hline & Mean(SD) \\
\hline \multirow[t]{2}{*}{ Age (17-72 years) } & 40.68 \\
\hline & Frequency (\%) \\
\hline \multicolumn{2}{|l|}{ Gender } \\
\hline M & 59.79 \\
\hline $\mathrm{F}$ & 40.21 \\
\hline \multicolumn{2}{|l|}{ Living place } \\
\hline Urban & 85.56 \\
\hline Rural & 14.43 \\
\hline \multicolumn{2}{|l|}{ Education } \\
\hline High school & 19.58 \\
\hline Postgraduate (Trade) school & 14.43 \\
\hline College & 54.63 \\
\hline Master Degree & 10.3 \\
\hline $\mathrm{PhD}$ & 1.03 \\
\hline \multicolumn{2}{|l|}{ Smoking in the past } \\
\hline No & 47.42 \\
\hline $1-5 y$ & 21.64 \\
\hline $5-10 y$ & 7.21 \\
\hline $10-20 y$ & 8.24 \\
\hline over20y & 15.46 \\
\hline \multicolumn{2}{|l|}{ Alcohol consumption } \\
\hline Several times a week & 6.18 \\
\hline Weekly & 8.24 \\
\hline Several times a month & 12.37 \\
\hline Monthly/on occasions & 12.37 \\
\hline Very seldom & 45.36 \\
\hline Never & 15.46 \\
\hline \multicolumn{2}{|l|}{ Sweets consumption } \\
\hline Daily & 23.71 \\
\hline Several times a week & 36.08 \\
\hline Weekly & 13.4 \\
\hline Several times a month & 13.4 \\
\hline Once in several months & 8.24 \\
\hline Several times a year & 5.15 \\
\hline \multicolumn{2}{|l|}{ Teeth brushing frequency } \\
\hline Once in several days & 2.06 \\
\hline Daily & 32.98 \\
\hline Twice a day & 60.82 \\
\hline Following each meal & 4.12 \\
\hline
\end{tabular}

The answers to the questions, evaluating the dentist and dental office related behavior, are presented in table II.

OHIP-14 Aesthetic subscale and overall scores means and standard deviations can be observed in table III.

RSES overall scores means and standard deviations can be observed in table IV. 
Table II. Interaction with the dentist, experience with the dental office.

\begin{tabular}{|c|c|c|c|c|c|}
\hline \multicolumn{6}{|c|}{ Last visit in the dental office } \\
\hline 1 month ago & 3 months ago & 6 months ago & 1 year ago & 2 years ago & Over 2 years ago \\
\hline 15.46 & 15.46 & 21.64 & 20.61 & 7.21 & 19.58 \\
\hline \multicolumn{6}{|c|}{ Dental visit frequency within the last 5 years } \\
\hline Never & Once a year & Twice a year & Once in three months & Once in 4 months & Another Answer \\
\hline- & 2.06 & 32.98 & 60.82 & 4.12 & - \\
\hline \multicolumn{6}{|c|}{ Traumatic experience in the dental office } \\
\hline \multirow{2}{*}{\multicolumn{2}{|c|}{$\begin{array}{l}\text { Never } \\
63.91\end{array}$}} & \multirow{2}{*}{\multicolumn{2}{|c|}{$\begin{array}{c}\text { Yes, during childhood } \\
19.58\end{array}$}} & \multicolumn{2}{|c|}{ Yes, during adulthood } \\
\hline & & & & \multicolumn{2}{|c|}{16.49} \\
\hline \multicolumn{6}{|c|}{ Do you get along with your dentist } \\
\hline & Yes & & \multicolumn{3}{|c|}{ No } \\
\hline & 95.87 & & \multicolumn{3}{|c|}{4.12} \\
\hline \multicolumn{6}{|c|}{ Did you avoid the dental visit } \\
\hline & Yes & & \multicolumn{3}{|c|}{ No } \\
\hline & 27.83 & & \multicolumn{3}{|c|}{72.16} \\
\hline
\end{tabular}

Table III. Univariate descriptive statistics - OHIP-14Aesthetic overall subscale scores.

\begin{tabular}{|c|c|c|c|c|c|c|c|c|}
\hline & $\begin{array}{l}\text { Functional } \\
\text { Limitation }\end{array}$ & $\begin{array}{l}\text { Physical } \\
\text { Pain }\end{array}$ & $\begin{array}{c}\text { Psychological } \\
\text { Discomfort }\end{array}$ & $\begin{array}{l}\text { Physical } \\
\text { Disability }\end{array}$ & $\begin{array}{l}\text { Psychological } \\
\text { Disability }\end{array}$ & $\begin{array}{c}\text { Social } \\
\text { Disability }\end{array}$ & Handicap & $\begin{array}{c}\text { Overall } \\
\text { OHIP- } \\
\text { 14Aestethic }\end{array}$ \\
\hline $\begin{array}{l}\text { Complete sample }(\mathrm{n}=97) \text {; } \\
\text { Mean (SD) }\end{array}$ & $\begin{array}{c}2.2 \\
(1.92)\end{array}$ & $\begin{array}{c}2.72 \\
(1.37)\end{array}$ & $\begin{array}{c}1.37 \\
(1.88)\end{array}$ & $\begin{array}{c}0.95 \\
(1.29)\end{array}$ & $\begin{array}{c}1.21 \\
(1.26)\end{array}$ & $\begin{array}{c}0.64 \\
(1.19)\end{array}$ & $\begin{array}{l}0.62 \\
(1.3)\end{array}$ & $\begin{array}{c}9.55 \\
(7.73)\end{array}$ \\
\hline $\begin{array}{l}\text { Male subjects }(n=39) \\
\text { Mean (SD) }\end{array}$ & $\begin{array}{c}1.74 \\
(1.69)\end{array}$ & $\begin{array}{c}2.1 \\
(1.29)\end{array}$ & $\begin{array}{c}0.82 \\
(1.48)\end{array}$ & $\begin{array}{c}0.51 \\
(0.94)\end{array}$ & $\begin{array}{c}0.84 \\
(0.96)\end{array}$ & $\begin{array}{c}0.56 \\
(1.14)\end{array}$ & $\begin{array}{c}0.35 \\
(0.84)\end{array}$ & $\begin{array}{c}6.94 \\
(5.67)\end{array}$ \\
\hline $\begin{array}{l}\text { Female subjects }(n=58) \text {; } \\
\text { Mean (SD) }\end{array}$ & $\begin{array}{l}2.55 \\
(2.01)\end{array}$ & $\begin{array}{l}3.13 \\
(1.27)\end{array}$ & $\begin{array}{c}1.74 \\
(2.03)\end{array}$ & $\begin{array}{l}1.25 \\
(1.40)\end{array}$ & $\begin{array}{c}1.46 \\
(1.39)\end{array}$ & $\begin{array}{c}0.70 \\
(1.22)\end{array}$ & $\begin{array}{c}0.81 \\
(1.52)\end{array}$ & $\begin{array}{l}11.31 \\
(8.45)\end{array}$ \\
\hline
\end{tabular}

Table IV. Univariate descriptive statistics - RSES question and overall scores.

\begin{tabular}{|l|c|c|c|c|c|c|c|c|c|c|c|c|} 
& $\mathbf{1}$ & $\mathbf{2}$ & $\mathbf{3}$ & $\mathbf{4}$ & $\mathbf{5}$ & $\mathbf{6}$ & $\mathbf{7}$ & $\mathbf{8}$ & $\mathbf{9}$ & $\mathbf{1 0}$ & \\
Complete sample (n= 97); & 3.34 & 3.5 & 3.47 & 3.47 & 3.42 & 3.53 & 3.4 & 2.34 & 3.77 & 3.5 & 33.77 \\
Mean (SD) & $(0.62)$ & $(0.75)$ & $(0.54)$ & $(0.61)$ & $(0.68)$ & $(0.73)$ & $(0.73)$ & $(0.94)$ & $(0.58)$ & $(0.66)$ & $(4.59)$ \\
Male subjects (n= 39); & 3.41 & 3.51 & 3.48 & 3.56 & 3.35 & 3.56 & 3.43 & 2.33 & 3.79 & 3.48 & 33.94 \\
Mean (SD) & $(0.67)$ & $(0.75)$ & $(0.50)$ & $(0.64)$ & $(0.74)$ & $(0.75)$ & $(0.71)$ & $(1.03)$ & $(0.52)$ & $(0.64)$ & $(4.2)$ \\
Female subjects (n= 58); & 3.29 & 3.50 & 3.46 & 3.41 & 3.46 & 3.51 & 3.37 & 2.34 & 3.75 & 3.51 & 33.65 \\
Mean (SD) & $(0.59)$ & $(0.75)$ & $(0.56)$ & $(0.59)$ & $(0.65)$ & $(0.73)$ & $(0.74)$ & $(0.88)$ & $(0.62)$ & $(0.68)$ & $(4.84)$
\end{tabular}

\section{Pearson correlations}

The following statistical significant correlations between the subscale/overall OHIP-14 Aesthetic scores and the questions/overall RSES scores were obtained:

- the psychological discomfort subscale scores with the "On the whole, I am satisfied with myself" ( $r=-0.258$, $\mathrm{p}=0.011)$, "I feel I do not have much to be proud of" ( $\mathrm{r}=$ $-0.330, p=0.001)$ questions scores and the RSES overall scores $(\mathrm{r}=-0.201, \mathrm{p}=0.49)$;

- the physical disability subscale scores with the "On the whole, I am satisfied with myself” ( $r=-0.330, p=0.001)$, "I feel I do not have much to be proud of" ( $r=-0.238$, $p$
$=0.019$ ), "I wish I could have more respect for myself" ( $\mathrm{r}$ $=-0.219, \mathrm{p}=0.031)$ questions scores and the RSES overall scores $(\mathrm{r}=-0.219, \mathrm{p}=0.031)$;

- the psychological disability subscale scores with the "On the whole, I am satisfied with myself" ( $r=-0.277$, $\mathrm{p}=0.006)$, "I feel I do not have much to be proud of" ( $\mathrm{r}$ $=-0.260, p=0.01)$, "I wish I could have more respect for myself" ( $\mathrm{r}=-0.245, \mathrm{p}=0.016)$ questions scores and the RSES overall scores $(r=-0.218, p=0.032)$;

- the social disability subscale scores with the "I feel I do not have much to be proud of' $(\mathrm{r}=-0.312, \mathrm{p}=0.002)$ question scores and the RSES overall scores $(r=-0.203, p=0.046)$; 
- the handicap subscale scores with the "I feel that I have a number of good qualities" $(r=-0.204, p=0.045)$, "I feel I do not have much to be proud of" $(r=-0.297, p$ $=0.003$ ), "I feel that I'm a person of worth, at least on an equal plane with others." $(\mathrm{r}=-0.267, \mathrm{p}=0.008)$, "I wish I could have more respect for myself" $(r=-0.234, p=0.021)$ questions scores and the RSES overall scores $(r=-0.237, p$ $=0.019$ );

- the overall OHIP-14 Aesthetic scores with the "I certainly feel useless at times" $(r=0.219, p=0.031)$ and the "I take a positive attitude toward myself" $(r=0.217, p$ $=0.033$ ) question scores.

The following statistical significant correlations between the subscale/overall OHIP-14Aesthetic scores and the dental hygiene/eating habits/dentist interaction questions scores were obtained:

- the functional limitation subscale with the "Last visit in the dental office" $(r=-0.262, p=0.010)$, "Did you avoid the dental visit" $(r=-0.310, p=0.002)$, "Traumatic experience in the dental office" $(r=0.278, p=0.006)$, "Do you get along with your dentist" $(r=-0.246, p=0.015)$ questions;

- the pain subscale with the "Alcohol consumption" $(\mathrm{r}=-0.207, \mathrm{p}=0.042)$ assessment question;

- the psychological discomfort subscale with the "Dental visit frequency within the last 5 years" $(r=0.288$, $\mathrm{p}=0.004$ ) question;

- the physical disability subscale with the "Did you avoid the dental visit" $(r=-0.217, p=0.033)$ question;

- the psychological disability subscale with the "Dental visit frequency within the last 5 years" $(\mathrm{r}=0.242$, $p=0.017)$, "Did you avoid the dental visit" $(r=-0.276, p$ $=0.006)$, "Traumatic experience in the dental office" $(\mathrm{r}=$ $0.225, p=0.027)$, "Alcohol consumption" $(r=-0.248, p=$ 0.014 ) questions;

- the social disability subscale with the "Dental visit frequency within the last 5 years" $(r=0.329, p=0.001)$ question;

- the handicap subscale with occupation $(r=-0.280$, $\mathrm{p}=0.005)$ and with the "Dental visit frequency within the last 5 years" $(r=0.226, p=0.026)$, "Last visit in the dental office" $(\mathrm{r}=0.22, \mathrm{p}=0.029)$ questions;

- the overall OHIP-14 Aesthetic score with the "Alcohol consumption" $(r=-0.226, p=0.026)$ assessment question.

\section{Inferential statistics - the t-test}

The t-test indicated statistically significant differences between male and female subjects, for the following OHIP-14 Aesthetic subscale scores: functional limitation subscale score $\mathrm{t}(95)=-2.057, \mathrm{p}=0.042$, pain subscale score $\mathrm{t}(95)=-3.896, \mathrm{p}=0.001$, psychological discomfort subscale score $\mathrm{t}(95)=-2.420, \mathrm{p}=0.017$, physical disability subscale score $\mathrm{t}(95)=-2.897, \mathrm{p}=0.005$, psychological disability subscale score $\mathrm{t}(95)=-2.417, \mathrm{p}$ $=0.018$. Differences were obtained also for the OHIP-14
Aesthetic overall score $\mathrm{t}(95)=-2.820, \mathrm{p}=0.006$.

The t-test did not indicate any statistically significant differences between male and female subjects, in respect to the RSES question scores and overall scores.

The t-test indicated statistically significant differences between male and female subjects, also for the "Dental floss usage" $t(95)=-2.373, p=0.020$, "Smoking frequency in the past" $t(95)=2.585, \mathrm{p}=0.011$, "Alcohol consumption" $\mathrm{t}(95)=6.487, \mathrm{p}=0.001$.

\section{Discussion}

The main purpose of the current study implied the assessment of the gender variations in dental aesthetics, OHRQoL and self-esteem, together with their interrelations.

Regarding the self-perception of the dental aesthetics and OHRQoL, the usage of the OHIP-14 Aesthetic led to the following observations: The OHIP-14 Aesthetic subscales, which registered the highest scores, for the complete sample, were functional limitation, pain and psychological discomfort. For the male subjects, the highest scored subscales were functional limitation, pain and psychological disability. For the female subjects, the highest subscale scores belonged to the functional limitation, pain and psychological discomfort subscales (mean subscale scores can be assessed in table I). The higher scores indicate more severe effects upon the OHRQoL. However, the resulted scores are smaller compared to other reported results, using the same instrument [37].

Related to the perception of the self-esteem, the usage of the RSES suggested the following observations: For the complete samples, the RSES questions which scored highest were "At times I think I am no good at all", "I certainly feel useless at times" and "All in all, I am inclined to feel that I am a failure". Regarding the male subjects, the highest question scores were registered for "At times I think I am no good at all", "I certainly feel useless at times" and "I am able to do things as well as most other people". Concerning the female subjects, the questions presenting the highest scores were "At times I think I am no good at all", "I feel that I have a number of good qualities", "I feel I do not have much to be proud of", "All in all, I am inclined to feel that I am a failure" and "I take a positive attitude toward myself" (mean question scores can be assessed in table II). The higher RSES scores indicated the perception of a higher selfesteem. The obtained overall scores are higher, compared to other literature reports [23], and approach the maximum threshold score of 40 , indicated that the subjects perceived a good self-esteem.

The differences in the perception of both dental aesthetics and OHRQoL, in relation to gender, were assessed by comparing the subscale and overall OHIP14 Aesthetic male and female subjects' scores. The t-test indicated statistically significant differences between the 
scores of the male and female subjects, for five of the OHIP-14Aesthetic subscale scores, as well as for its overall scores. These differences can be extensively assessed within the results section. Accordingly to the OHIP14Aesthetic scores, within the present study, the female subjects presented the self-perception of worsened dental aesthetics and OHRQoL.

The studies which use the OHIP-14Aesthetic questionnaire are limited in literature, no gender differences regarding the self-perception of dental aesthetics, using this questionnaire, have bee reported so far. However, statistically significant differences in the perception of the OHRQoL have been reported using the original long OHIP-49 form, which OHIP-14Aesthetic was derived from. In one study, female subjects reported the perception of a more altered OHRQoL, compared to male subjects [38]. Similar with the current study, in respect to the dental aesthetics, a more critical approach for the female subjects was reported, but with the usage of another selfreporting instrument [39]. In other studies, female subjects tended to be more critical in the evaluation of the smile and dental aspects [39], dental color [40] or when answering combined dental aesthetics and OHRQoL questionnaires [41]. In contrast to the present study, other research protocols indicate no gender-related statistically significant OHRQoL perception differences, using different forms of the OHIP questionnaire [42].

The differences in the perception of the self-esteem in relation to gender were investigated by comparing the overall RSES male and female scores. The t-test did not highlight any overall scores differences in respect to subject gender. This finding is in consistency with other study results, which report no self-esteem differences related to gender, both in dental patients [23] and general patients [18].

The interrelation between dental aesthetics/ OHRQoL and self-esteem has been investigated through the Pearson correlations, calculated between the subscale/ overall OHIP-14Aesthetic scores and the RSES question and overall scores. Five of the OHIP-14Aesthetic subscale scores were statistically significant correlated with RSES question scores and RSES overall scores. Moreover, the overall OHIP-14Aesthetic score was statistically significant correlated with RSES question scores. All the obtained correlations were negative, meaning that low OHIP-14Aesthetics scores were correlated with high RSES scores. Thus, the perception of satisfactory dental aesthetics and OHRQoL was correlated with a high self-esteem. The complete set of correlations was extensively presented in the results section.

Interrelations between dental aesthetics, OHRQoL and self-esteem have been statistically significant suggested in similar studies, as well, both in regard to dental aesthetics-self-esteem [21,29] and in regard to OHRQoL-self-esteem, using either OHIP forms $[22,28]$ or other instruments $[21,23]$.
The interrelation between the OHRQoL and eating/ habits, dental hygiene habits, the interaction with the dentist has been evaluated through the Pearson correlations, calculated between the subscale/overall OHIP-14Aesthetic scores and the scores of the questions assessing the above mentioned elements. All of the subscales, together with the overall OHIP-14Aesthetic score correlated statistically significant with the scores belonging to questions such as: "Last visit in the dental office", "Traumatic experience in the dental office", "Do you get along with your dentist", "Did you avoid the dental visit" or "Traumatic experience in the dental office". Alcohol consumption was as well related to the OHIP-14Aesthetic subscale and overall scores. The complete set of correlations was extensively presented in the results section.

The perception of a good OHRQoL, which correlated with a high self-esteem, can be partially explained by the samples current characteristics: the majority of the sample live in an urban environment, implying higher access to health care services (indicated? by the sample's overall high dental visit frequency); the majority of the sample has college educational degree; the highest percent of the sample reported no smoking and reduced alcohol consumption; the majority of the sample reported a high teeth brushing frequency.

The current results can also be explained by the following limits of the present study: the usage of a convenience, small sized sample, together with the interviewers' reduced degree of experience in such studies, as the interviewers were represented by second year students. Further research on larger and more diversified samples as well systematic teaching in the questionnaire appliance are needed.

\section{Conclusions}

Within its limitations, the current study indicates that the self-perception of the dental aesthetics and OHRQoL interrelate with one person's self-esteem. However, the strength of this relations has been found to be reduced. Additionally, self-perception was proved to vary by gender, in the assessment of the dental aesthetics and OHRQoL.

\section{References}

1. Gift HC, Atchison KA, Dayton CM. Conceptualizing oral health and oral health-related quality of life. Soc Sci Med. 1997;44:601-608.

2. Reissmann DR, John MT, Feuerstahler L, Baba K, Szabó $\mathrm{G}$, Čelebić A, et al. Longitudinal measurement invariance in prospective oral health-related quality of life assessment. Health Qual Life Outcomes. 2016;14:88. .

3. Isiekwe GI, Sofola OO, Onigbogi OO, Utomi IL, Sanu OO, daCosta OO. Dental esthetics and oral health-related quality of life in young adults. Am J Orthod Dentofacial Orthop. 2016;150:627-636. 
4. Klages U, Bruckner A, Zentner A. Dental aesthetics, selfawareness, and oral health-related quality of life in young adults. Eur J Orthod. 2004;26:507-514.

5. Da Costa AC, Rodrigues FS, da Fonte PP, Rosenblatt A, Innes NPT, Heimer MV. Influence of sense of coherence on adolescents' self-perceived dental aesthetics; a crosssectional study. BMC Oral Health. 2017;17(1):117. doi: 10.1186/s12903-017-0405-2.

6. Momeni Danaei S, Salehi P. Association between normative and self-perceived orthodontic treatment need among 12- to 15-year-old students in Shiraz, Iran. Eur J Orthod. 2010;32:530-534.

7. Mugonzibwa EA, Kuijpers-Jagtman AM, van't Hof MA, Kikwilu EN. Comparison between the opinions of Tanzanian parents and their children on dental attractiveness. Angle Orthod. 2004;74:63-70.

8. John MT, Reissmann DR, Čelebić A, Baba K, Kende D, Larsson $\mathrm{P}$, et al. Integration of oral health-related quality of life instruments. J Dent. 2016;53:38-43.

9. Slade GD, Spencer AJ. Development and evaluation of the Oral Health Impact Profile. Community Dent Health. 1994;11:3-11.

10. Yule PL, Durham J, Playford H, Moufti MA, Steele J, Steen N, et al. OHIP-TMDs: a patient-reported outcome measure for temporomandibular disorders. Community Dent Oral Epidemiol. 2015;43:461-470.

11. Allen F, Locker D. A modified short version of the oral health impact profile for assessing health-related quality of life in edentulous adults. Int J Prosthodont. 2002;15:446-450.

12. Wong AH, Cheung CS, McGrath C. Developing a short form of Oral Health Impact Profile (OHIP) for dental aesthetics: OHIP-aesthetic. Community Dent Oral Epidemiol. 2007;35:64-72.

13. Rogers CR. Client-centered therapy. New York: HoughtonMifflin; 1951: pp. 597-515.

14. Paz V, Nicolaisen-Sobesky E, Collado E, Horta S, Rey C, Rivero M, et al. Effect of self-esteem on social interactions during the Ultimatum Game. Psychiatry Res. 2017;252:247255 .

15. Geukes K, Nestler S, Hutteman R, Dufner M, Küfner ACP, Egloff B, et al. Puffed-up but shaky selves: State self-esteem level and variability in narcissists. J Pers Soc Psychol. 2017; 112:769-786.

16. Glendinning A. Family life, health and lifestyles in rural areas: the role of self-esteem. Health Education. 1998;98:59. 68 .

17. Trzesniewski KH, Donnellan MB, Moffitt TE, Robins RW, Poulton R, Caspi A. Low self-esteem during adolescence predicts poor health, criminal behavior, and limited economic prospects during adulthood. Dev Psychol. 2006;42:381-390.

18. Murray SL, Rose P, Bellavia GM, Holmes JG, Kusche AG. When rejection stings: how self-esteem constrains relationship-enhancement processes. J Pers Soc Psychol. 2002;83:556-573.

19. Orth U, Robins RW, Roberts BW. Low self-esteem prospectively predicts depression in adolescence and young adulthood. J Pers Soc Psychol. 2008;95:695-708.
20. Somerville LH, Kelley WM, Heatherton TF. Self-esteem modulates medial prefrontal cortical responses to evaluative social feedback. Cereb Cortex. 2010;20:3005-3013.

21. Agou S, Locker D, Streiner DL, Tompson B. Impact of selfesteem on the oral-health-related quality of life of children with malocclusion. Am J Orthod Dentofacial Orthop. 2008;134:484-489.

22. Clijmans M, Lemiere J, Fieuws S, Willems G. Impact of self-esteem and personality traits on the association between orthodontic treatment need and oral health-related quality of life in adults seeking orthodontic treatment. Eur J Orthod. 2015;37:643-650.

23. Chin LSH, Chan JCY. Self-esteem, oral health behaviours, and clinical oral health status in Chinese adults: An exploratory study. Health Education Journal. 2012;72:684694.

24. Gavric A, Mirceta D, Jakobovic M, Pavlic A, Zrinski MT, Spalj S. Craniodentofacial characteristics, dental estheticsrelated quality of life, and self-esteem. Am J Orthod Dentofacial Orthop. 2015;147:711-718.

25. Eberl C, Winkler I, Pawelczack S, Tröbitz E, Rinck M, Becker ES, et al. Self-esteem consistency predicts the course of therapy in depressed patients. PloS One. 2018;13:e0199957.

26. Iancu I, Bodner E, Ben-Zion IZ. Self esteem, dependency, self-efficacy and self-criticism in social anxiety disorder. Compr Psychiatry. 2015;58:165-171.

27. Carvalho IG, Bertolli ED, Paiva L, Rossi LA, Dantas RA, Pompeo DA. Anxiety, depression, resilience and selfesteem in individuals with cardiovascular diseases. Rev Lat Am Enfermagem. 2016;24:e2836. doi: 10.1590/15188345.1405.2836.

28. Özhayat EB. Influence of self-esteem and negative affectivity on oral health-related quality of life in patients with partial tooth loss. Community Dent Oral Epidemiol. 2013;41:466672 .

29. Venete A, Trillo-Lumbreras E, Prado-Gascó VJ, Bellot-Arcís C, Almerich-Silla JM, Montiel-Company JM. Relationship between the psychosocial impact of dental aesthetics and perfectionism and self-esteem. J Clin Exp Dent. 2017;9:e1453-e1458.

30. Afroz S, Rathi S, Rajput G, Rahman SA. Dental esthetics and its impact on psycho-social well-being and dental self confidence: a campus based survey of north Indian university students. J Indian Prosthodont Soc. 2013;13:455-460.

31. Klages U, Erbe C, Sandru SD, Brüllman D, Wehrbein H. Psychosocial impact of dental aesthetics in adolescence: validity and reliability of a questionnaire across age-groups. Qual Life Res. 2015;24:379-390.

32. Bleidorn W, Arslan RC, Denissen JJ, Rentfrow PJ, Gebauer JE, Potter J, et al. Age and gender differences in self-esteem-A cross-cultural window. J Pers Soc Psychol. 2016;111:396410.

33. Gebauer JE, Sedikides C, Wagner J, Bleidorn W, Rentfrow PJ, Potter J, et al. Cultural norm fulfillment, interpersonal belonging, or getting ahead? A large-scale cross-cultural test of three perspectives on the function of self-esteem. J Pers Soc Psychol. 2015;109:526-548. 
34. Locker D. Measuring oral health: a conceptual framework. Community Dent Health. 1988;5:3-18.

35. Rosenberg M. Society and the adolescent child. Princeton, NJ: Princeton University Press; 1965: pp. 326.

36. Wongpakaran T, Wongpakaran N. A comparison of reliability and construct validity between the original and revised versions of the Rosenberg Self-Esteem Scale. Psychiatry Investig. 2012;9:54-58.

37. Fernández E, Bersezio C, Bottner J, Avalos F, Godoy I, Inda $\mathrm{D}$, et al. Longevity, Esthetic Perception, and Psychosocial Impact of Teeth Bleaching by Low (6\%) Hydrogen Peroxide Concentration for In-office Treatment: A Randomized Clinical Trial. Oper Dent. 2017;42:41-52.

38. Séculi E, Fusté J, Brugulat $P$, Juncà $S$, Rué M, Guillén M. Health self-perception in men and women among the elderly.
Gac Sanit. 2001;15:217-223.

39. Armalaite J, Jarutiene M, Vasiliauskas A, Sidlauskas A, Svalkauskiene V, Sidlauskas M, et al. Smile aesthetics as perceived by dental students: a cross-sectional study. BMC Oral Health. 2018;18:225. doi: 10.1186/s12903-018-0673-5.

40. Tin-Oo MM, Saddki N, Hassan N. Factors influencing patient satisfaction with dental appearance and treatments they desire to improve aesthetics. BMC Oral Health. 2011;11:6. doi: 10.1186/1472-6831-11-6.

41. Liepa A, Urtane I, Richmond S, Dunstan F. Orthodontic treatment need in Latvia. Eur J Orthod. 2003;25:279-284.

42. Rodakowska E, Mierzyńska K, Bagińska J, Jamiołkowski J. Quality of life measured by OHIP-14 and GOHAI in elderly people from Bialystok, north-east Poland. BMC Oral Health. 2014;14:106. 